\title{
El concepto de la crónica: una mirada desde los aportes de las ciencias sociales y humanas
}

Recibido: 21 de marzo de 2019

Aceptado: 20 de mayo de 2019

Publicado: 24 de junio de 2019
Javier Franco Altamar

jfranco@uninorte.edu.co

Universidad del Norte (Colombia)

Resumen: Se reflexiona sobre el concepto de la crónica latinoamericana a partir del entendido de que, para construirlo, no basta con lo testimonial, sino que deben tomarse en cuenta criterios adicionales desde las teorías de la narración, la literatura, la psicología social, la antropología simbólica y la etnografía. A eso se agregan las contribuciones de las tendencias periodístico-literarias de corte norteamericano, las cuales (a su vez) se nutrieron de los abordajes de la novela realista europea del siglo XIX. El resultado es un concepto en el cual la crónica queda ubicada como un género de corte creativo y narrativo, con una voz y un tono particular de marcada influencia literaria, con el cual se recrea la realidad acontecida (ya sea personaje, lugar, situación o acontecimiento), tanto desde los factores de interés clásicos del periodismo, como desde la cotidianidad significativa.

Palabras clave: Crónica, periodismo literario, narración, géneros periodísticos, Latinoamérica.

Abstract: We reflect on the concept of the Latin American chronicle from the understanding that to build it, testimonial is not enough, but that additional criteria must be taken into account from the theories of narration, literature, social psychology, anthropology symbolic and ethnography. To this are added the contributions of the journalistic-literary tendencies of the North American style, which, in turn, were nourished by the approaches of the nineteenth-century European realist novel. The result is a concept in which the chronicle is located as a genre of a creative and narrative nature, with a particular voice and tone of marked literary influence, with which the reality that is recreated-be it character, place, situation or event-, both from factors of typical interest from journalism, as from the meaningful everyday life.

Key words: Chronicle, literary journalism, narrative, journalistic genres, Latin America. 


\section{Introducción: la necesidad de superar el testimonio}

San Agustín (2007) expone lo siguiente: “¿Qué es, pues, el tiempo? Si nadie me lo pregunta, lo sé; pero si quiero explicárselo al que me lo pregunta, no lo sé” (p. 224). De esa manera, pone de presente la dificultad en que siempre se halla el usuario del lenguaje para encontrar, en la oferta del mismo (es decir, en sus términos y combinaciones) lo más adecuado y preciso para reconvertir en palabras lo que ya es una representación mental.

Porque el concepto es eso: una representación mental asociada a un significante lingüístico, dice en nuestro caso el Diccionario de la Real Academia de la Lengua Española. Es equivalente, en algunos aspectos, a "significado", pero como advierte Montalbetti (2011), por esta vía de la sinonimia se corre el riesgo de entrar en un juego circular que nos conduce al punto de partida. Esto se da, explica Montalbetti, porque cualquier cosa que se ponga luego del enunciado "el significado es..." o es incorrecta o es circular. Lo primero asociado a la particularidad de que el lenguaje debe estudiarse con lenguaje. Eso lo convierte en juez y parte; y al no poder ser examinada la palabra con un instrumento exterior, pues entenderla implica echar mano de interconexiones complejas entre sentidos conformados, a su vez, por otras palabras. Esto, al final, no esclarece nada, sino que vuelve más complejo el asunto. Y lo segundo, porque si se usa el mecanismo de invocar un sinónimo como solución (y se pasa así del uno al otro), el resultado es un regreso al término inicial, de lo que resultaría que "el significado es el significado".

El significado o concepto remite a una representación mental, una idea ubicada dentro de la conciencia. Es lo único claro en toda esta discusión que, en el caso de nuestra civilización occidental, viene desde la Grecia antigua. Es un debate que pasó, como casi todo lo fundamental de nuestro modelo de entendimiento, por Aristóteles. Son reconocidos los esfuerzos de taxonomía del Estagirita incluso en el lenguaje. Así, nos ha proporcionado la famosa noción de verdad por correspondencia, en el sentido de que lo evaluable como verdadero ha de ser el enunciado en la medida en que respeta esa relación entre el lenguaje y la realidad referida.

Wittgenstein (1988) sostiene que en muchos casos en los que empleamos el término "significado" (no en todos, advierte), este puede definirse así: "el significado de una palabra es el uso que se hace de ella en el lenguaje" (p. 61). Por eso, el filósofo austríaco recomienda no preguntar tanto por el significado de una palabra, como por su uso.

Esta mirada hacia el papel del lenguaje, de su uso en la producción de los significados sobre el supuesto de que no existen previamente de forma natural (el ámbito de la pragmática) aparece también en Derrida (1971). En su filosofía tributaria de Heidegger, el pensador francés no solo rebautiza como "deconstrucción" la destrucción heideggeriana, sino que acuña la expresión différance (o 'Diferencia', así con la "e" aumentada en la traducción de Oscar del Barco y Conrado Ceretti) para dar cuenta de la producción de significados.

En esa palabra, se combinan dos acepciones del verbo "diferir": el de la exclusión espacial (basada en las diferencias) y de la temporal, basada en el aplazamiento. Así, de acuerdo 
con Derrida, para reconocer el significado de una palabra no solo nos basta con que sea diferente de otra, sino que deben tenerse en cuenta las consideraciones contextuales de su uso.

Dicho de otra manera, solo es posible reconocer el significado de un término cualquiera cuando este se encuentre en un contexto. Esto quiere decir que el sentido de una palabra (que sería el equivalente de un concepto), una frase, una oración, o un texto completo no surge de él, de forma espontánea e inmediata, sino que el sentido va a depender de lo que cada futuro de signos posteriores le proporcionen en contextos de interpretación. Si eso es así, ¿qué uso le estamos dando a la palabra “crónica”? ¿A qué sentido le estamos apuntando en Latinoamérica?

En nuestra región, la palabra "crónica" remite a un texto periodístico que se construye con el uso de las herramientas expresivas propias y originales de la literatura. En otros ámbitos (como, por ejemplo, el español) se habla directamente de "periodismo literario" en una relación que co-descendencia con la literatura, más concretamente, con la novela realista. Por esa vía conceptual, bajo el mismo paraguas, caben las expresiones del "Nuevo Periodismo" norteamericano de la década de 1970; y el "reportaje personal" de la década del ochenta del mismo siglo, que era considerada obra de "periodistas literarios". Las investigaciones de Rotker (2005), apuntan no solo por esos lados, sino a la aparición de los poetas modernos de Latinoamérica, cuya pluma (al incursionar en el periodismo) trajo consigo los mecanismos expresivos propios del poema y de allí vino lo que hoy tenemos como "crónica".

El trabajo que presentamos a continuación, que retoma líneas de un trabajo anterior del autor (Franco, 2017), pero que actualiza, amplía y profundiza otros aspectos del mismo, apunta justamente a eso. El objetivo es precisar los alcances de la definición de la palabra "crónica", aunque, por supuesto, debemos reconocer también nuestras limitantes epistemológicas; es decir, hasta dónde tenemos capacidad de llegar en ese propósito.

Es claro, como se viene diciendo desde los racionalistas (con el liderazgo de Spinoza) que no podemos abarcarlo todo con el entendimiento, que tenemos un acceso limitado a la realidad porque somos finitos y estamos ubicados en un espacio y tiempo específicos; pero, como a su vez apunta Duch (1997), sí debemos ser capaces de enfrentar los imponderables humanos y las contingencias a partir de "criterios". Y sobre esta base, con criterios firmes, y con el convencimiento pleno de nuestras acciones, es que se construye "testimonio", entendido, si se quiere, como una coherencia entre lo que se hace y se dice. Un verdadero maestro, sentencia Duch, debe primero creerse su propio discurso, y sobre eso, brindar un testimonio que trasmita criterios, o ayude a formarlos. Porque el ser del testimonio se encuentra presente en su decir y su hacer:

"En el testimonio, la palabra humana adquiere toda su fuerza y toda su realidad. En efecto, en el arte de testimoniar, la palabra se muestra plenamente autosuficiente, no necesita elementos ajenos que le otorguen validez y justificación” (Duch, 1997, p. 126). 
Los mismos cronistas latinoamericanos, a partir de sus propias experiencias, han dado testimonio. Ese es un buen punto de partida. A todos se les puede tener como maestros y ya observaremos cómo cada cual proporciona criterios que apuntan a uno u otro aspecto de la crónica; y que, por la vía del uso del lenguaje, entrecruzan géneros, complementan, delimitan, categorizan, suman, excluyen, incorporan o descartan. Algunos brindan su testimonio desde la pura experiencia; otros, desde la lectura de quienes le precedieron; y los demás, en combinación de ambas fuentes con diferentes proporciones. Nosotros, en complemento, podemos avanzar, ayudar a pulir, a delimitar. Este es el objetivo de este trabajo: contribuir para que queden saldadas las disparidades, los distanciamientos y las abiertas contradicciones que pueden haber surgido de los bien intencionados testimonios. En ese sentido, son útiles y esclarecedoras las reflexiones y contribuciones desde ámbitos complementarios, sobre todo de las ciencias sociales y las humanidades.

\section{Mitología y etimología}

La palabra crónica nos remite, primero, a Khronos, una expresión griega que significa "tiempo", y que, dada una similitud fonética, es muy fácil de confundir con el nombre de Crono, personaje mitológico de una generación previa a la de los tres grandes dioses hermanos: uno de ellos Zeus, el del Olimpo. La primera obligación etimológica, entonces, es no ceder a la tentación de asociar a la crónica con este personaje, que, en la Teogonía de Hesíodo figura como uno de los doce titanes, hijo menor de Urano y Gea, la Tierra ${ }^{1}$.

Por Hesíodo (quien escribió en 700 a. C.) también nos enteramos de que Crono (Saturno en la adaptación mitológica romana) llegó a regir entre los inmortales. El final de su poder coincide con el nacimiento de Zeus, el último de sus hijos, el único que no alcanzó a ser presa de su voracidad celestial aniquiladora de herederos. Desde entonces Crono, derrotado, desbancado por su hijo, se instaló en el Lacio, junto al amable rey Jano, y por el resto de la eternidad, se dedicó a enseñar. Esa es, por lo menos, una de las versiones mitológicas.

Cada uno de estos personajes adopta su imagen específica y diferenciada en el entendimiento del griego de la época, y Crono, que en Teogonía aparece como el de "mente retorcida", no es la excepción: se le representa como un anciano flaco y triste con una hoz en la mano, el arma de la castración, correspondiente después con la idea de los ciclos de las cosechas. Por allí, quizás, es por donde comienza la confusión: dado que la dinámica del cultivo se rige por ciclos regulares, no fue sino un leve movimiento conceptual para que remitiera al paso del tiempo. Los egipcios y los babilonios fueron los primeros, hace unos 5000 años, en medir el tiempo para organizar la actividad agrícola. Tomaron como base la observación del firmamento, el paso de las estaciones y el comportamiento de los ríos al lado de los cuales florecieron como civilizaciones.

1 Su importancia en la mitología radica en que un buen día a Gea le dieron ganas de deshacerse de Urano, o de tan siquiera frenar su dinámica e insaciable capacidad de reproducción. Para ello, acudió a sus hijos en busca de apoyo, y solo uno de ellos dio el paso al frente: Crono, el último de la lista. Con una hoz proporcionada por su propia madre, Crono le tendió una trampa a Urano y lo castró. Del espumarajo que cayó en los mares, se dice, surgió Afrodita, la diosa del amor (Venus para los romanos) 
Los romanos respetaron y adaptaron, más adelante, los inventos y descubrimientos asociados con eso (Souvirón, 2012a, 2012b). En la Edad Media, todavía se ve que varios acontecimientos, entre ellos justamente ese paso de las estaciones (Duch, 2015), servían para establecer pautas de servicio a la vida cotidiana. Eso constituía el referente de tiempo de los agricultores y campesinos, que nunca sabían la hora exacta, pero se apoyaban, para tener una idea, en los toques de campana de la iglesia parroquial, el canto de las aves o el curso del sol.

Pero no por estos giros semánticos, datos históricos y confusiones de homonimia, debe declararse a Crono como Dios del tiempo. Es más, su nombre, explica Souvirón (2008), podría de significar "cuervo":

\footnotetext{
En efecto, a Crono suele representársele como un cuervo, igual que después a Apolo con una corneja (latín, cornix; griego, koronís). El cuervo, como otras aves de la familia de los córvidos, es un ave oracular y, por tanto, se le atribuyen cualidades cercanas a la inteligencia. La perspicacia de estas aves parece estar detrás del dicho romano, atestiguado por Cicerón, cornicum oculos configere, cuya traducción literal es "vaciar los ojos las cornejas", es decir, engañar a los más perspicaces (p. 95).
}

La palabra Khronos, en cambio, sí nos remite a tiempo: Chroniká ( $\chi \rho \circ v$ có) corresponde a $[\beta \imath \beta \lambda i ́ \alpha]$ Biblia, o libro escrito en orden cronológico. En su forma adjetiva es $\chi \rho \circ \imath \iota \kappa o ́ \varsigma$ chronikós. Y cuando ya Roma, luego del periodo helenístico pasa a reemplazar a Grecia en la historia, a esta condición se denomina chronı̌cus. De esa manera, se denomina "cronista" a todo aquel que, al usar la palabra como instrumento de fijación en secuencia de algo que ya pasó.

\footnotetext{
Me gusta la palabra “crónica". Me gusta, para empezar, que en la palabra "crónica” aceche Cronos, el tiempo. Siempre que alguien escribe, escribe sobre el tiempo, pero la crónica (muy en particular) es un intento siempre fracasado de atrapar el tiempo en que uno vive. Su fracaso es una garantía: permite intentarlo una y otra vez, y fracasar e intentarlo de nuevo, y otra vez (Caparrós, 2016, p. 432).
}

De hecho, cuando aparecieron los primeros escritos asociados con la idea del desplazamiento en el tiempo, pasaron a denominarse "crónicas" en idioma castellano. Por eso es considerado "cronista" el poeta Teognis de Mégara, a quien los estudiosos de la Grecia antigua le deben parte del acceso a lo ocurrido en la época de los tiranos (Souvirón, 2016, p. 446); también Esdras, a quien se le atribuye la autoría de los dos libros de Crónicas del Antiguo Testamento en la Biblia judeo-cristiana (siglos IV y III A.C.); y hasta Quinto Curcio Rufo, el historiador romano por quien han llegado a nuestros días episodios formidables de la vida de Alejandro Magno.

Es claro, entonces que la crónica, en su acepción primigenia de reconstrucción de acontecimientos del pasado fijados por escrito es más antigua que el periodismo, actividad a la que terminaría incorporada porque siempre, desde la aurora de sus usos, el relato tipo crónica ha remitido a la reproducción de hechos reales, de cosas que de verdad ocurrieron, y que son traídas al presente en respeto de su ruta original sobre el tiempo. La crónica, sin embargo, no es el equivalente a un texto histórico, sino una aproximación, en cuanto relato, 
a uno de sus muchos matices o dimensiones posibles desde un narrador: uno de los colores de ese gran espectro blanco que es la historia.

\begin{abstract}
El cronista es el narrador de la historia. Puede evocarse otra vez en el pasaje de Hebel, que tiene de punta a cabo el acento de la crónica, y medir sin esfuerzo la diferencia entre el que escribe la historia, el historiador, y el que la narra, es decir, el cronista. El historiador está supeditado a explicar de una u otra manera los sucesos de los que se ocupa; bajo ninguna circunstancia puede contentarse con presentarlos como dechados del curso del mundo. Pero precisamente eso hace el cronista, y de manera especialmente enfática, sus representantes clásicos, los cronistas de la Edad Media, que fueron los precursores de los posteriores historiógrafos (Benjamin, 2008, p. 77).
\end{abstract}

Si bien el tiempo subyace como elemento capital en el texto tipo crónica, ya no lo hace en respeto riguroso al flujo del insumo histórico, sino incorporado según los criterios y límites creativos del relator o cronista. En el periodismo moderno, como bien apuntan Ronderos, León, Sáenz, Grillo \& García (2002) la crónica perdió su camisa de fuerza cronológica y evolucionó hasta convertirse en un territorio sin fronteras, cuyo autor, si seguimos a Benjamin (2008), es “quien toma lo que narra de la experiencia, de la suya propia o la referida. Y la convierte, a su vez, en experiencia de aquellos que escuchan su historia” (p. $65)$.

En consecuencia, un primer aspecto a considerar en la construcción del concepto de la crónica es que su abordaje y construcción remiten a la narración como forma comunicacional. Es decir, más allá de que como expresión periodística deba responder a una lista de criterios en lo que se impone, sobre todo, lo novedoso (ya sea en contenidos o enfoques); la crónica es un texto narrativo. Dada esa condición, participa de unas características y alcances que no deben pasarse por alto.

Duch (2012) ha enfatizado que la temática en torno a la narración posee una excepcional importancia para la comunicación ya que es una pieza fundamental tanto para los procesos de construcción de la identidad individual y colectiva como para el mantenimiento y la recreación de una determinada tradición. Los humanos tenemos una continua necesidad de narraciones para presentarnos y representar a los otros y a nosotros mismos, descubriendo al mismo tiempo nuestra propia mortalidad (Duch, 2012). Y para ello se remite a la tensión natural, jamás resuelta, entre mythos y logos, que más que excluyentes son caras de una misma moneda. Es un aspecto también desarrollado por Bruner como la dicotomía pensamiento paradigmático (logos en este caso) versus pensamiento narrativo (mythos) desde la psicología popular.

La narración, a juicio de Duch (2012), es un "universal humano" (p. 255), posee la virtud de exteriorizar y de representar los "procesos pulsionales y cerebrales que, pese a las diferencias de carácter cultural e histórico, son comunes a todos los miembros de la familia humana. Y, además, lo sepamos o no, lo queramos o no, "vivimos siempre en un mundo narrado y los comentarios que sobre y de él hacemos, ya sea en clave histórica o en clave cuentística, son otras narraciones, otras historias, y así ad infinitum" (Duch, 2008, p. 197). 
Este autor conviene con Benjamin en que si bien toda narración muestra un gran interés por las historias, no suele tener ninguna atención especial por la Historia como discurso científico. Este discurso, dice Duch (2012):

\footnotetext{
Se expresa en tercera persona porque el historiador intenta (otra cosa es si lo consigue) mantener una neutralidad en forma de lejanía científica y emocional respecto a los acontecimientos o los personajes historiados. En cambio, el narrador, explícita o implícitamente, se mueve dentro del marco de la segunda persona (tú, nosotros o el yo como tú) porque el objetivo de su ejercicio narrativo consiste en crear una atmósfera común, unas complicidades experienciales, un círculo amoroso pregunta-respuesta entre él mismo y quienes le escuchan (p. 256).
}

$\mathrm{Y}$ en quienes lo leen, en el caso de la crónica periodística, que como género ha significado el retorno a la magia narrativa. En este caso hablamos de un dispositivo que, desde los tiempos de los mitos griegos, canalizó la imposición de los modelos culturales sobre los cuales se construyó la civilización occidental (Souvirón, 2006). Porque los mitos se expresan con narración, y basan su eficacia en la imagen, más contundente para fijar algo en la mente que cualquier argumentación.

La crónica, como todo relato, remite a la imaginación y en eso reside su fuerza. Seduce en cuanto relato, apunta hacia un lado distinto al de la explicación, más útil en el territorio de los intelectuales y de los estudiosos. Se supone que el lector de crónicas, por ser esta un texto periodístico, viene de cualquier parte y es heterogéneo. Un relato está más a su alcance, es más sencillo de digerir: solo hay que imaginar.

\section{Los cronistas y sus miradas}

Cada investigador, docente, periodista o teórico tiene su propio concepto de lo que es la crónica, lo cual, a su vez, se desprende de cada experiencia, como hemos dicho antes. Por esa misma naturaleza, el concepto suele quedar atrapado en la trampa de lo anecdótico, y a veces las discusiones terminan zanjándose sobre la base de que la división en géneros no solo es imposible, sino innecesaria porque "lo importante es que la historia esté bien contada", se oye decir. Pero para avanzar en la construcción de un concepto más cercano a la verdad de la crónica, un buen punto de partida es considerar estar miradas particulares, escuchar esas voces para ir cuadrando, puliendo, definiendo. Tomemos como base, para ello, un ejercicio previo realizado por Franco (2017) y que reproducimos, con los ajustes respectivos a donde haya lugar, en los mismos términos y orden:

Empecemos por un artículo publicado en el diario La Nación de Argentina (2006), reproducido, más adelante en una antología de Jaramillo (2012). En esta pieza, se ensaya una perspicaz definición de la crónica que remite a la hibridez del género, mezcla equilibrada y armónica, que se configura sobre la base de lo que le aportan otros géneros, algunos, incluso, ajenos al periodismo y anteriores a él: 
Si Alfonso Reyes juzgó que el ensayo era el centauro de los géneros, la crónica reclama un símbolo más complejo: el ornitorrinco de la prosa. De la novela extrae la condición subjetiva, la capacidad de narrar desde el mundo de los personajes y crear una ilusión de vida para situar al lector en el centro de los hechos; del reportaje, los datos inmodificables; del cuento, el sentido dramático en espacio corto y la sugerencia de que la realidad ocurre para contar un relato deliberado, con un final que lo justifica; de la entrevista, los diálogos; y del teatro moderno, la forma de montarlos; del teatro grecolatino, la polifonía de testigos, los parlamentos entendidos como debate: la "voz de proscenio", como la llama Wolfe, versión narrativa de la opinión pública cuyo antecedente fue el coro griego; del ensayo, la posibilidad de argumentar y conectar saberes dispersos; de la autobiografía, el tono memorioso y la reelaboración en primera persona. El catálogo de influencias puede extenderse y precisarse hasta competir con el infinito. Usado en exceso, cualquiera de esos recursos resulta letal. La crónica es un animal cuyo equilibrio biológico depende de no ser como los siete animales distintos que podría ser (Villoro, 2012, p. 578).

Otro aspecto es la narración en primera persona, o cuando menos, la aparición explícita del autor del texto: "La crónica está ligada a la voz de quien escribe. Es un flujo narrativo que recuerda un poco a los cuentos de la abuela" (Samper, 2001, p. 14). El mencionado autor se preocupa por definir la crónica como un escrito que suele entrar en consideraciones "de carácter general" y con un tono distinto al del reportaje. Lo curioso, sin embargo, es que para distinguir un género del otro, identifica en el reportaje características claras de la crónica latinoamericana actual: separar un hecho o un personaje, y recrearlo. Para hacerlo, el cronista se vale "de la referencia de detalles personales o circunstancias de anotaciones impresionistas, y de la pintura del ambiente, con el fin de comunicar al lector una idea redonda sobre lo que es materia de la nota" (Samper, 2001, p. 15).

Dentro de su concepto de la crónica, Samper (2001) subraya en la condición del paso del tiempo, lo mismo que en su frescura y aparente espontaneidad, con énfasis en la carga personal de su abordaje. Por lo que la crónica sería, como bien apuntó el escritor y periodista austríaco Erich Hackl durante un conversatorio en Cartagena: "La mirada subjetiva de un hecho real" (Cartagena, 2007) en el recinto de la Universidad Tecnológica de Bolívar, durante un homenaje a Ryszard Kapuściński, con la participación de varios teóricos y escritores que conocieron su obra. Saad (2007) reprodujo apartes de la ponencia de Hackl en estos términos:

[Su fórmula creativa es] acercarse al tema desde la óptica del escritor para buscar mis personajes y mis historias. Después viene el problema de encontrar la forma para contar esa historia. Me gusta compartir con las personas (con las víctimas), su dolor, su ideología y me gusta que ellos sientan que de alguna forma los estoy acompañando. Trato de llenar mis historias con hechos, personajes y diálogos reales. Hago novelas basándome en las técnicas del reportaje literario y cuando, por necesidad estética o falta de información sólo hay literatura en algunos fragmentos de mis escritos, procuro dejar claro que sólo es un punto de vista personal (el mío) sobre algo que pudo haber pasado. Hay que ser honestos, eso es lo que en verdad importa (p. 11).

Eso reitera la importancia capital de la percepción del cronista, que no esconde (como sí se pretende en los géneros noticiosos e incluso en el reportaje clásico) la presencia y contribución del autor. 
Debido a esta manera de presentación, la crónica establece un contrato especial con el lector, una relación mágica por su poder evocador, por estar preñada de significado social, por ser una gran metáfora que permite no solo el disfrute a partir de lo que dice o denota, sino en lo que genera o connota. En este aspecto, resulta vital la participación del lector, porque él es quien recrea en su mente las escenas, las imágenes o la atmósfera, mientras avanza conectado con los estímulos del texto. Alguien lo va guiando, y en ese sentido, el texto va mostrando referencias de una experiencia personal que no por serlo está dejando de ser fiel a la realidad.

En ese sentido, Guillermoprieto, citada por Guardela (2001), plantea que en la noticia "el periodista está contestándole preguntas al lector; mientras que en la crónica está generando información que jamás se le hubiera ocurrido a ese lector". Pero para que el cronista logre eso, agrega Guillermoprieto, citada por Guardela (2001), primero tiene que sentir la historia, tiene que "caminar" sobre ella, para contarla desde una voz clara, testimonial, la misma subjetividad que pesa y le da su valor fundamental a la crónica:

La característica principal de la crónica es la intimidad. La crónica es una forma de vivir la vida y la escritura. Es salir a la calle, hacerse permeable, transparente a la vida que nos rodea, es vulnerabilidad absoluta ante la vida. Y es escribir desde adentro de la piel. Es caminar y vivir y luego cronicar. Es colocarse en una condición de riesgo, de vulnerabilidad emocional, de rabia (Guardela, 2001, p. 1).

Su forma de presentación, su estructura, el orden libre que plantea sobre la base de las escenas, es lo que inscribe a la crónica bajo el paraguas de la modalidad conocida como "periodismo narrativo". Destacamos que Tomás Eloy Martínez, uno de los históricos maestros de la Fundación para el Nuevo Periodismo Iberoamericano (FNPI), indicaba que a diferencia del "trabajo seco" del tradicional noticioso, en el relato periodístico narrativo hay una "voz subjetiva", aunque la diferencia más importante es la presencia, en el periodismo narrativo (y sobre todo la crónica, podría enfatizarse), de uno a varios relatos particulares que ejemplifican una situación general (Meneses, 2004).

Sobre la condición narrativa de la crónica, a Gabriel García Márquez se le atribuye una sentencia en el sentido de que la crónica "tiene la técnica del cuento, con la diferencia de que los hechos son ciertos". Sea cierta en sentido literal o no, hay algo de ella en su célebre respuesta a un lector en la desaparecida revista Cambio y que fue reproducida por Sala de Prensa. El texto, titulado Sofismas de distracción (2001) es un tanteo a la diferencia entre los géneros periodísticos y cuando García Márquez habla del reportaje como su género preferido, señala: "Puede ser igual a un cuento o una novela con la única diferencia (sagrada e inviolable) de que la novela y el cuento admiten la fantasía sin límites, pero el reportaje tiene que ser verdad hasta la última coma. Aunque nadie lo sepa ni lo crea" (García Márquez, 2001). Pero, a renglón seguido, hace una salvedad:

\footnotetext{
Nunca se aprenderá a distinguir a primera vista entre reportaje, crónica, cuento y novela. Pregúnteselo a los diccionarios y se dará cuenta de que son los que menos lo saben. Es un problema de métodos: todos los géneros mencionados tienen sus puertos de abastecimiento en investigaciones y testimonios, en libros y documentos, en interrogatorios y encuestas, y en la creatividad torrencial de la vida cotidiana (García Márquez, 2001).
} 
Al tomar como punto de partida sus propias obras para entrar a diferenciarlas o ubicarlas en el género más cercano, García Márquez (2001) menciona a Relato de un náufrago como un reportaje que está "más cerca de la crónica, porque es la trascripción organizada de una experiencia personal contada en primera persona por el único que la vivió". García Márquez, en esencia, no ayuda a esclarecer mucho la diferencia, aunque apunta a una consideración estructural asociada a la secuencia. En ese caso, la crónica, en cuanto relato secuencial, toma prestadas las herramientas expresivas del cuento en términos de escenas, descripción, diálogos, cambios de planos y ritmos, pero sobre los insumos de la realidad: cada palabra debe corresponder con lo que está queriendo decir de la vida real.

Lo mostrado por la crónica puede ser o bien una persona, un animal, un lugar, un acontecimiento o una situación. En los tres primeros casos (persona o animal) puede hasta hablarse de "personaje", y el texto pasaría a tener una fuerte o predominante carga descriptiva. Con el resto, la balanza se inclina, y la carga más significativa pasa a ser de la narración o la prosa reflexiva en sus variados matices. La circunstancia principal que motiva a la reproducción de ese "algo" es el interés que despierta. Eso significa que la crónica está condicionada, en principio, por los clásicos criterios de interés periodístico; aunque en un panorama ampliado también tienen cabida personajes, situaciones, lugares y acontecimientos que no clasificarían como interesantes para el periodismo tradicional, pero que como de todos modos se han configurado o construido sobre la base de sus propios elementos dramáticos, generan otros detonantes para la crónica. A ese sentido, del que hemos hablado antes con la ayuda de Bruner, apunta el concepto de Daniel Samper Ospina:

Hacer crónicas que no tienen raíz en la coyuntura, aunque sí en la cotidianidad, es como descubrir tréboles de tres hojas: son ordinarios, pero fabulosos. Un trébol de tres hojas necesita los mismos milagros del sol y la clorofila que uno de cuatro, pero no suele ser tomado en cuenta. El periodismo narrativo es la manera de reivindicar la importancia de los tréboles de tres hojas (Abad et al., 2004, p. 96).

Este ámbito común entre el periodismo y la literatura, en el que se mezclan la forma expresiva de las artes escritas con la vida real como materia de trabajo, es el ámbito privativo de la crónica. En eso, los más variados conceptos confluyen. Son mezclas que más bien deberían ser consideradas como "préstamos" entre géneros, que se manifiestan y operan después de que el autor ha escogido el género que mejor le funciona para sus propósitos. Luego de eso, puede incluir, en su relato, elementos propios de otros géneros para conseguir mayor efectividad o contundencia.

Ramírez (2007) resalta la necesidad de que se produzca este "préstamo mutuo", porque si bien al cronista le está vedado inventar, o nada la impide formular un relato atractivo, dinámico que termine con un golpe maestro. "Es llevar la técnica del narrador de ficción a la realidad" y concluyó que la nueva historia no está siendo escrita por los historiadores, sino por los buenos cronistas de nuestros tiempos.

"La crónica se constituye en un espacio de condensación por excelencia [...] porque en ella se encuentran todas las mezclas, siendo ella la mixtura misma convertida en unidad singular y autónoma" (Rotker (2005, p. 53). Al hacerlo, explora el campo específico de 
este género como mezcla entre el periodismo y la ficción, que se desprende de la práctica literaria y se introduce al mercado a manera de arqueología del presente. En esa condición, se dedica a narrar y mostrar lo que está al "margen" de las grandes noticias con el ánimo no tanto de informar, sino de divertir. Otros investigadores (como González, 1983 y Ramos, 2003) ubican en la expresión modernista de finales del siglo XIX la fuente de la crónica moderna latinoamericana, y afirman que con este género se produce un desplazamiento desde la ficción a la realidad. Eso, de alguna manera, pone a la crónica en el mismo nivel y orden de las piezas literarias.

A la crónica, la delimita también su movimiento en equilibrio sobre la línea fronteriza entre la narrativa de ficción y el trabajo de campo del periodismo. Una línea que separa o acerca los dos oficios según se le mire, pero que no debe llamar a confusiones. Al respecto, Guerriero (2015), para quien la crónica habita dentro el periodismo narrativo, y este, a su vez, dentro del ámbito del arte, anota lo siguiente:

Quizás por eso, porque el buen periodismo narrativo puede definirse como arte y porque utiliza recursos de la ficción, es que a veces las cosas se confunden. Porque de todos los recursos de la ficción que puede usar, hay uno que al periodismo narrativo le está vedado. Y ese recurso es el recurso de inventar (p. 44).

Es una condición que, vista desde el periodismo, no comparte con ningún otro género. Aunque eso no quiere decir que no apoye a los otros cuando lo amerite o lo requiera, situación que también ocurre en sentido contrario, cuando el reportaje o la entrevista (por mencionar dos de los más cercanos) necesitan conectarse con el lector de una manera distinta y creativa. Caparrós (2016) asegura:

El cronista mira, piensa, conecta para encontrar (en lo común) lo que merece ser contado. Y trata de descubrir a su vez en ese hecho lo común: lo que puede sintetizar el mundo. La pequeña historia que puede contar tantas. La gota que es el prisma de otras tantas (p. 434).

Es un género de no ficción, sigue Caparrós (2016), en el que la escritura pesa más porque la crónica aprovecha la potencia del texto, la capacidad de hacer aquello que ninguna infografía, ningún cable podrían: armar un clima, crear un personaje, pensar una cuestión. Un texto lleno de magia, agrega, capaz de conseguir que un lector se interese en una cuestión que en principio no le interesaba en lo más mínimo (p. 435).

Salcedo (2011), el más representativo de los actuales cronistas colombianos, resalta el componente humano siempre presente en las crónicas. Su axioma de que "la crónica es el rostro humano de la noticia", responde a su forma predilecta de asumir los temas, la de tomar como eje narrativo una historia personal que lo ejemplifica, una vivencia en torno a la cual se van desarrollando las diferentes aristas, los contextos y los tiempos de la historia. Esa arquitectura garantiza la solidez del relato, lo mantiene compacto y permite, de paso, conectar a los lectores con mayor fuerza. En ese sentido, el personaje actúa como si fuera un pretexto para contar algo más, para abrir el lente. $\mathrm{Y}$ aun cuando ese personaje sea lo principal, es decir, que mostrarlo sea la intención del cronista, no deja de aprovecharse el texto para enmarcarlo en sus significados, en lo que lo descifra como personaje. "La 
crónica es, además, la licencia para sumergirse a fondo en la realidad y en el alma de la gente" (Salcedo, 2011, p. 125).

En este momento de nuestro recorrido conceptual, es necesario hacer una precisión territorial: debido a su particular desarrollo, su especial abordaje y la contribución de nuestras más grandes plumas, no es atrevido afirmar que, tal y como se ha desplegado su majestad, la crónica es un género "sudaca". Caparrós (2016), hace uso intencional de ese término despectivo europeo para resaltar la fuerza latinoamericana de la crónica. De hecho, esta identificación geográfica ha encontrado eco en algunos teóricos y cultores de la crónica, incluso los de otros lares.

Gil González (2004) asegura que la crónica está pertrechada de herencias, tanto históricas como literarias. "Todas esas esquirlas han dado lugar a la formación de un género periodístico sui generis, propio, auténtico, autónomo y genuinamente latino, ya que no tiene correspondencia con ningún género del periodismo anglosajón (story y comments)" (p. 35). Y añade que la crónica es una desviación del modelo canónico del periodismo. Esta singularidad y no homologación con los textos anglosajones, agrega, es más una ventaja que un inconveniente, puesto que resalta la ambigüedad y ambivalencia de este género. "En una época de acelerados cambios y en una etapa eminentemente crucial del periodismo, necesitamos un género dúctil, maleable, con capacidad para adaptarse a todas las circunstancias imaginables sin perder su sello característico" (Gil González, 2004, p. 35), remata.

Dentro de un marco teórico más exigente (Cristoff, 2016), Callegaro \& Lago (2012) recalcan que la crónica latinoamericana es un "cruce entre literatura, periodismo y análisis social" (p. 246) Agregan que como textos, muchas veces las crónicas llegan a constituir un acto de intervención en un sentido performativo; una operación de interpelación ética que actúa e intercede para que se produzca el encuentro entre el lector y aquello que permanece invisible o lo que no se quiere ver. Piezas con registro más cercano a lo literario que a lo periodístico, mediante la elección de puntos de vista múltiples, a partir de diferentes técnicas de ficcionalización (Callegaro \& Lago, 2012, p. 261).

MartínezAlbertos (1974) enfatiza en que la crónica es un producto literario predominantemente latinoamericano. Al definirla, dice que se trata de una narración directa e inmediata de una noticia con ciertos elementos valorativos, que siempre deben ser secundarios respecto a la narración del hecho en sí (p. 123). También enfatiza en la "hibridez" del género, en el sentido de que está a medio camino entre los informativos y los “editorializantes", con la voz subjetiva manifiesta e inevitable, que termina respondiendo a la "reacción visceral" (Guardela, 2001) del cronista en su primer contacto con el sitio donde recogerá los datos.

La primera reacción visceral del sitio a donde llega el periodista es oro molido para la crónica. Es lo más precioso del hecho de reportear. El cuaderno de apuntes se llena invariablemente más al principio que al final del viaje porque todo es nuevo, todo es interesante, y todo es motivo de reflexión. Esas primeras reacciones son oro molido porque le darán al texto la textura y la calidad de crónica (Guardela, 2001, p. 3). 
Con todo este amplio telón de fondo de miradas, apreciaciones, consideraciones, experiencias, puntos de vista y reflexiones particulares, ya es posible ir estrechando los límites del concepto de la crónica a partir de las coincidencias. Lo primero es que la crónica, entendida plenamente como un género latinoamericano, tiene una ubicación particular (como punto de encuentro, si se quiere, entre la literatura y el periodismo). Eso llevaría a definirla, en un principio, como un texto, tipo relato, que reconstruye o representa, mediante el uso del lenguaje, un hecho, un personaje, un lugar o una situación correspondientes con una realidad acontecida. Al recurrir, en su expresión escrita, a las herramientas de la literatura, la crónica se constituye en una mirada específica de esos hechos reales, personalizada y marcadamente subjetiva, pues está matizada por los enfoques, los puntos de vista, las percepciones y reflexiones del autor.

La presencia de una "voz", entonces, es lo que viene a diferenciar a la crónica de otros géneros más "objetivos" debido a la participación evidente y clara de ese "alguien” que, como autor, guía el desplazamiento por la lectura. Eso no quiere decir que la crónica deje de responder a los interrogantes clásicos del periodismo, pero se concentra más en el "cómo". Eso, al menos expuesto en términos de contrastes y purezas que más adelante examinaremos, aparta a la crónica del reportaje, género este más enfocado en el 'por qué', en la explicación, en las conexiones entre causas y consecuencias, y en la exploración de las aristas de los grandes temas.

\section{Género y narrativa}

En el desarrollo de estas reflexiones hemos dado en referirnos a la crónica como un "género" y hasta parece indiscutible que lo es. De manera que, en aras de avanzar hacia una mejor definición, es conveniente examinar este aspecto. Así, en primer lugar, los "géneros del periodismo" deben entenderse como una adecuación de los géneros de la expresión artística ya identificados desde la primera clasificación de Aristóteles en el siglo V a. C. a partir de su análisis de la tragedia y la épica. Es una disposición cuyos límites se han venido purificando con valiosas contribuciones como las de Genette (1991) y que, en el plano de la teoría periodística, ha tenido toda suerte de abordaje en los manuales, en tratados de referencia como los de Grijelmo (1997) y Bastenier (2001). Este último en particular, sobre la base del ejercicio en el diario El País, de España. En este punto no está de más resaltar que si bien Bastenier identifica como características del reportaje lo que le atribuimos a la crónica en Latinoamérica, es particularmente orientador cuando determina los límites entre los géneros. Así, este autor distingue entre los géneros "secos", de enfoque informativo puro, despersonalizado; y los géneros de mayor intervención personal del periodista, en un grupo en los que caben la crónica y el reportaje (Bastenier, 2001, p. 32).

Como advierte Serrano (1997), "los diferentes libros de texto a los cuales recurre un profesor presentan una gama de definiciones y categorías, dependiente de quien escribe y del lugar de donde procede el autor" (p. 108), ante lo cual, el docente debe utilizar el modelo que más ilustre las circunstancias y necesidades del país (o de la región, 
según el caso). Estas consideraciones, agrega, llevan a que se acuda a etiquetar con un término un conjunto de textos a partir de los rasgos similares que comparten; o se atienden, para hacerlo, su funcionamiento particular. Esta mirada comparativa, que a Besa (2014) le sirvió para ubicar mejor al ensayo dentro de la taxonomía de los géneros literarios; también nos ayuda a ubicar a la crónica dentro de los géneros periodísticos, una adaptación conceptual en el plano de lo que Chillón (2014) denomina "texto fáctico".

En este respecto resulta orientador el enfoque de Grijelmo (1997), quien subraya como principal criterio para establecer estas divisiones entre géneros, el mayor o menor grado de subjetividad plasmado en el texto (p. 25). Así, mientras se avanza sobre una línea imaginaria definida por el respeto a la verdad (entendida esta, desde la explicación de Aristóteles, como cualidad del enunciado), un primer bloque queda conformado por los relatos fácticos de corte informativo. Son textos que pretenden figurar como despersonalizados, en los cuales la incorporación expresa de un narrador en primera persona es inimaginable. Luego, en la medida es que se incorporan elementos de decisión personal, iniciativas y enfoques, se pasa a los géneros narrativos/creativos.

En esta parcela, a diferencia de los productos textuales respetuosos de los cinco interrogantes tradicionales, se ubican textos de una más marcada dosis de creatividad ( $\sin$ decir que los informativos no la tengan, pero la carga es menor), con licencia para la incorporación expresa de una voz narrativa. Y luego, ya con la balanza cargada hacia una subjetividad mayor en términos de juicios, argumentaciones y valoraciones, están los géneros de opinión, que agrupa a editoriales, columnas y similares.

En ese sentido, lo más recomendable para efectos conceptuales, es situar a la crónica en la parcela del medio, junto con el reportaje y la entrevista, haciendo las salvedades para diferenciarlos entre ellos (figura 1). Estas diferencias suelen ser difíciles de apreciar en algunas piezas que parecen de todo un poco. No obstante, esas diferencias son claramente distinguibles cuando, en el caso del reportaje, se trate de un relato revelador de datos "ocultados" (tipo periodismo investigativo) o cuando el texto esté construido en formato de análisis. Esto último ocurre con los informes interpretativos, especializados en explicar los significados de las noticias, sobre todo en los campos complejos de la economía, la política y la justicia. Son textos en los que priman las conexiones entre los datos, las explicaciones, las citas y la aproximación a las consecuencias del hecho noticioso (Fagoaga, 1982). 
Figura 1: Desplazamiento desde los géneros objetivos hacia los más subjetivos.

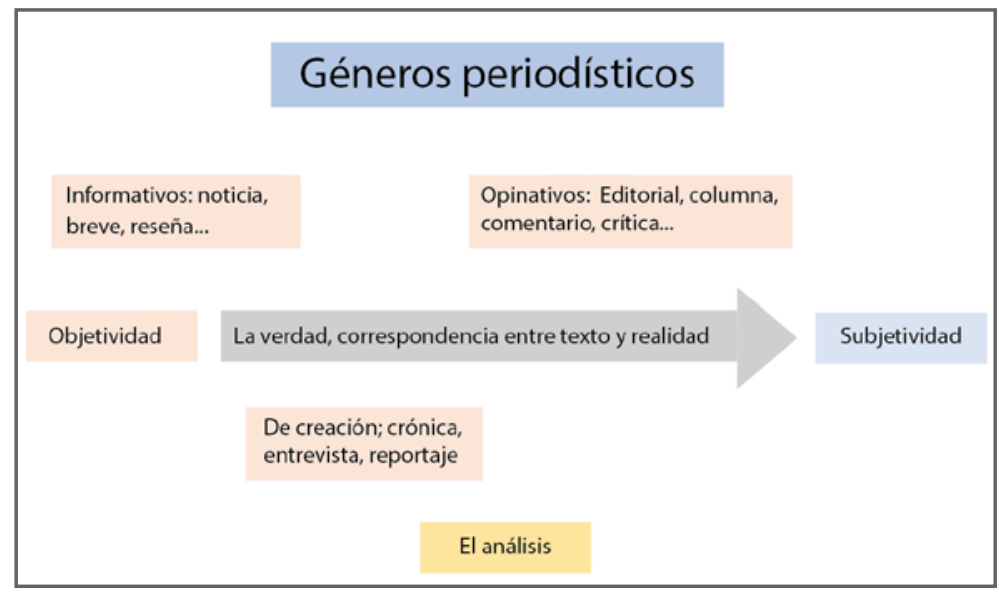

Fuente: Elaboración propia.

Entonces en cuanto texto periodístico, ya tenemos claro que la crónica debe ser ubicada bajo el paraguas de los narrativos. Pero como no todas las crónicas están elaboradas en forma de relatos puros, ni todas avanzan en orden secuencial al ritmo de una historia extensa como telón de fondo (ya algo de esto habíamos advertido antes), toca hacer algunas salvedades y precisiones antes de continuar.

En esa línea, Bruner (1986) plantea que (a diferencia de los vastos conocimientos que tenemos sobre el funcionamiento del razonamiento lógico y científico distintivo del pensamiento "paradigmático") sabemos muy poco sobre la manera de hacer buenos relatos. Y señala que en todo relato deben construirse, de manera simultánea, dos panoramas: uno, el de la acción; y el otro, el de la conciencia.

El primero apunta a lo formal en la estructura del texto, su "gramática particular" en términos de agentes, intención o meta, situación o instrumento. Es lo que remite a la denominada "Péntada dramatúrgica", de Kenneth Burke, y que Bruner (1990) toma como punto de partida, pero que le parece insuficiente. Este esquema ubica el elemento dramático en el problema o desajuste que pueda presentarse en el equilibrio natural de estos elementos cuando se desarrolla un hecho. De aquí se desprende una característica crucial de los relatos en el sentido de que se especializan en elaborar un vínculo entre lo excepcional y lo corriente. Así, un relato actúa como reajuste de ese equilibrio porque se orienta a regresar al ámbito de lo canónico o admisible lo que en apariencia no lo era.

Con el otro plano, Bruner (1990) va un poco más allá de la péntada burkeana e incorpora el ámbito de la conciencia, que remite a lo que saben, piensan o sienten, o dejan de saber, pensar o sentir quienes intervienen en la acción. En este sentido, asegura Bruner (2013), la realidad síquica (la dimensión de la conciencia) predomina en la narración, y toda realidad que exista más allá del conocimiento de quienes intervienen en el relato, es puesta allí por el autor con el propósito de crear un efecto dramático adicional. 
El plano de la conciencia es clave para Bruner (1990), quien sostiene que el objeto de la narrativa está en las vicisitudes de las intenciones humanas, que se hacen visibles a través de situaciones como la búsqueda de objetivos, la persistencia de vencer obstáculos o la investigación, y se perciben como dirigidos por la intención. De esta manera, la fábula del relato (es decir, su tema subyacente atemporal) vendría a ser una unidad que contiene un conflicto en el cual los personajes se hallan como consecuencia de intenciones frustradas. Y esa frustración responde ya sea a las circunstancias, al carácter de los personajes o, más probablemente, a la interacción de ambos. En resumen, los tres elementos interactúan para darle unidad al relato en una estructura con comienzo, desarrollo y un "sentido de final". A este respecto, Bruner (1990) señala:

Quizá su propiedad más importante (la de los relatos) sea el hecho de que son inherentemente secuenciales: una narración consta de una secuencia singular de sucesos, estados mentales, acontecimientos en los que participan seres humanos como personajes o actores. Estos son sus componentes. Pero estos componentes no poseen, por así decir, una vida o significado propios. Su significado viene dado por el lugar que ocupan en la configuración global de la totalidad de la secuencia: su trama o fábula (p. 56).

Y aquí viene la necesaria claridad en el caso de la crónica: si bien estos criterios de Bruner (1990), que funcionan igual para relatos reales o imaginarios, ajustan a la perfección en una crónica que reproduce, en esencia, un acontecimiento o una secuencia de hechos, el balance entre ellos cambia cuando el relato ya no es tan narrativo, sino más bien descriptivo. Es el caso de una crónica que pretenda mostrar un espacio, un lugar (un barrio, una ciudad, un entorno cualquiera), para lo cual los otros elementos se incorporan en función de ese objetivo central. Igual pasa si el relato busca mostrar a un personaje, hacer un retrato global de él incluso en términos de lo que se denomina un perfil. En este caso, las características del personaje, sus diferentes dimensiones, su apariencia, sus aspectos sicológicos y demás, prevalecen en términos descriptivos, y entonces los demás ingredientes se incorporan en función de esos propósitos. Así, una vida ya resuelta en presente, puede aparecer expuesta como una secuencia de hechos, conflictos y vicisitudes pasadas; y además proyectada hacia las contingencias del futuro. Porque, como dice el mismo Bruner (1990) al hablar del alcance de las narraciones, explica que estas

no pueden reducirse meramente a la estructura de su trama o al dramatismo. Ni puede decirse que no sean más que "historicidad" o diacronicidad. También son una manera de usar el lenguaje. Ya que parece que su efectividad depende [...] de su "literariedad", incluso al relatar sucesos cotidianos. Las narraciones dependen en una medida sorprendente del poder de los tropos, es decir, de la metáfora, la metonimia la sinécdoque, la implicación y demás figuras. Sin ellos, las narraciones pierden su poder de "ampliar el horizonte de posibilidades", de explorar todo el espectro de conexiones entre excepcional y lo corriente (p. 69).

Otro aspecto a tener en cuenta en el juego de los planos de conciencia es la eventual participación del cronista no sólo como narrador, sino como personaje del relato. Es una incorporación sobre la que se discute mucho en escenarios académicos, pero que suele quedar plenamente justificada cuando la realidad síquica del autor, en cuanto actor, entra en conflicto con los acontecimientos de los que participa. Eso plantea un elemento dramático adicional que hace más interesante el relato, porque entre más desajustes entren en juego, ya sea entre los elementos de la péntada o desde las conciencias de los personajes, mejor suerte le espera al relato para con su lector. 
Con respecto a la entrevista como género (no como herramienta para conseguir datos), es necesario precisar: una cosa es el texto que reproduce, de manera rigurosa o lineal, una conversación; y otra muy distinta el que "matiza" o "romancea" ese diálogo intercalándolo con escenas, explicaciones, miradas panorámicas y antecedentes. En lo segundo, ese diálogo reproducido entra en juego como eje, como ruta sobre la cual se mueve el relato. La conversación, en este caso, actúa como línea orientadora, rectora del orden, que permite, de acuerdo siempre con los propósitos y estilo del autor, ir incorporando los demás elementos del relato.

\section{Encuentros, avances y proyecciones}

Según Barisone (2003), en la prensa de fines del siglo XIX se perfilan dos tipos de periodistas: uno más moderno, el reporter, vinculado más con la transmisión directa de noticias, y que actúa según el modelo de Estados Unidos; y está el otro de marcada influencia francesa, inclinado más a informar sobre el arte, la moda, y la vida cotidiana. Estos últimos producían notas de color que combinaban información con las impresiones personales, lo que constituyó un espacio interesante para los periodistas poetas. Como la crónica viajera ocupaba lugares de privilegio, y nuestros escritores modernistas fueron eternos migrantes (Martí, Darío, Gómez Carrillo), se produjeron textos fascinantes de marcado sello latinoamericano, así el escenario de los relatos fueran otros lugares del mundo. En este sentido, agrega Barisone (2003), "resultan ejemplares la serie de crónicas de José Martí referidas a los Estados Unidos, las de Enrique Gómez Carrillo surgidas de sus viajes por Japón, China, la India; y las de Rubén Darío sobre París y diversas ciudades de España e Italia” (p. 4).

Rokter (2005) subraya, en este aspecto, que en la génesis de la crónica modernista se presupone cierta tensión entre concepciones y funciones textuales diferentes: Por un lado, la necesidad de informar, propia de la función periodística; y por el otro, la búsqueda estética inherente a su condición de poetas. Dicho, en otros términos, la propensión a la autonomía estética, por una parte, y la exigencia de utilidad y entretenimiento derivada de un soporte destinado al consumo diario y masivo, por el otro. Esta tensión se resuelve, según Rotker (2005), en las crónicas mejor logradas de la época, de manera que tenemos a la crónica modernista como un género de carácter heterogéneo, ubicado en un lugar intermedio entre el discurso literario y el periodístico, con predominantemente matriz narrativa, pues relata hechos dando la ilusión de un desarrollo cronológico, lo que la convierte, si se quiere, en un género literario más.

Por otro lado, se suma un fenómeno periodístico surgido hacia la mitad de la década de 1970 en Estados Unidos: el denominado "Nuevo Periodismo": según Wolfe (1976), arrebata el centro de creación literaria a la "esterilizada y agonizante novela" y se convierte en el género literario más rico de la época. Para los "nuevos periodistas", que se sumergían donde "pasaban las cosas", el más adecuado proceder era "tomar contacto con completos desconocidos, meterse en sus vidas de alguna manera, hacer preguntas a las que no tenías derecho natural a tener respuesta, pretender ver cosas que no se tenían 
por qué ver, etc.” (pp. 76-77) y ante la incapacidad de los novelistas para enfrentarse al cambio vertiginoso experimentado por la sociedad norteamericana: "tuvieron, para ellos solos, los locos años sesenta, obscenos, tumultuosos" (p. 49).

Grandes ejemplos de este fenómeno son los textos de Truman Capote, empezando por su famoso libro A Sangre fría; y los de Gay Talese, con Honrarás a tu padre. Con ellos como máximos representantes de una rotulación de la que Talese se burla, el "Nuevo Periodismo", explica Wolfe (1976), retomó la tradición de la gran novela realista de siglos precedentes:

\footnotetext{
Si se sigue de cerca el progreso del Nuevo Periodismo a lo largo de los años sesenta, se observará un hecho interesante. Se observará que los periodistas aprenden de las técnicas del realismo (particularmente las que se encuentran en Fielding, Smollet, Balzac, Dickens y Gogol) a base de improvisación. A base de tanteo, de "instinto" más que de teoría, los periodistas comenzaron a descubrir los procedimientos que conferían a la novela realista su fuerza única variadamente conocida como "inmediatez", como "realidad" concreta, como "comunicación emotiva", así como su capacidad para "apasionar" o absorber (p. 50)
}

Bajo la influencia de estos periodistas de Norteamérica, nuestros propios cronistas empezaron a usar los cuatro procedimientos estructurales identificados y enunciados por Wolfe en 1973, fecha de la primera edición en inglés: la construcción escena por escena, el registro del diálogo, el punto de vista en tercera persona y el retrato global detallado del personaje, de las situaciones y el ambiente.

Las investigaciones de Chillón (2014) apuntan en ese sentido: el 'periodismo literario' (como prefiere denominarlo), es hermano de la novela moderna y tan hijo, como ella, de la novela realista europea del siglo XIX. Este abordaje, explica este autor, estaba impregnado de consciencia histórica y sociológica: presentaba individuos concretos que actuaban en el ambiente social y que eran influidos por él, hasta el punto de que la adecuación de las ficciones narrativas que tejían a la realidad social se convirtió en el eje principal de su valor artístico. Las novelas realistas querían ser verosímiles, representar, de modo fiel, tipos humanos y situaciones sociales realmente existentes. La ilusión de realidad que se empeñaba en infundir en los nuevos públicos burgueses se adecuaba a la exigencia de realidad de estos (p. 171). Y si bien la novela realista no descubrió el realismo, tan antiguo como el arte literario, sí le otorgó una dimensión inédita: no se trataba ya de un realismo superficial o parcial, limitado a la descripción cómica de los medios sociales bajos, sino de un realismo problemático, cada vez más consciente de la complejidad de las transformaciones sociales de la época.

Cuando Chillón (2014) explica estas conexiones con la novela realista, sentencia que lo correcto es hablar de "periodismo literario", ámbito dentro del cual cabe la crónica latinoamericana. El autor prefiere eso a "conceptos confusos y equívocos" como los de "periodismo narrativo" o de "textos de no ficción" (pp. 33-35). Sobre el primero, asegura que todo periodismo está planteado de manera narrativa en su esencia; y por lo segundo, 
redefine la palabra 'facticia' para esa manera de dar cuenta (o cuento, dice él) de la realidad con las herramientas canónicas de la literatura. Porque en la elaboración de esos relatos, es imposible no usar la fantasía o la invención partiendo de que el relato es ya una creación, una construcción que representa la realidad, pero que no equivale a ella misma. $\mathrm{Y}$ en su criterio, el uso de la denominación "crónica" para designar manifestaciones periodístico-literarias en esta parte del continente, es vaga e ilimitada, consecuencia de la "sombra" producida por las investigaciones de Rotker (2005) ya mencionadas.

Algo de eso también trae a colación Palau Sampio (2018) cuando señala que bajo el paraguas conceptual de la crónica hay tres modalidades: una ligada a la actualidad, de carácter más breve; una segunda asociada a producciones de largo aliento, profundas, investigadas, polifónicas; y una tercera que remite a textos de corte más ensayístico en los que el referente informativo es más bien el punto de partida. Esta autora aborda un interesante trabajo de definición que, sin embargo, no se despega de las solas contribuciones de la teoría literaria y de los testimonios de la periodística. Sin embargo, se resalta en su trabajo que, desde la perspectiva española, el término crónica responde a la primera modalidad, a diferencia de lo que ocurre con el abordaje latinoamericano, que parece, más bien, apuntarle a una combinación.

Pero más allá de que las reflexiones de Chillón (2014) sean o no discutibles desde el filtro conceptual de Rotker (2005), sí son muy valiosas en rigor investigativo, y aportan un telón de fondo contra el cual caben autores de gran vuelo narrativo en lo periodístico, y que empezaron a presentar trabajos asumibles como predecesores y fundadores de la narración periodística. Digno de mencionar es John Hersey, quien escribió un extenso texto titulado Hiroshima publicado en 1946 en la revista New Yorker, convertido, más adelante, en un exitoso libro recomendado hoy en cualquier curso de crónica que se respete. Es un texto que relata, de manera simultánea, la historia de seis personas de diferentes oficios con detalles sobre su vida, antes y después de caída la bomba atómica de Estados Unidos al final de la Segunda Guerra Mundial. La publicación significó una apuesta nueva de la revista en un formato y extensión que no le era afín.

Con todos estos elementos como telón de fondo Jaramillo (2012) le concede el punto de partida conceptual de nuestra crónica latinoamericana a Carlos Monsiváis, a quien considera uno de sus padres fundadores. Es Monsiváis, nos recuerda Jaramillo, quien define la crónica como la "reconstrucción literaria de sucesos o figuras, género donde el empeño formal domina sobre las urgencias informativas" (Jaramillo, 2012, p. 12). Y también nos dice que fue Monsiváis quien planteó para la crónica un vaivén histórico a lomo, primero, de los conquistadores españoles, con punto altos y bajos (p. 12). Luego menciona a los costumbristas del siglo XIX, quienes le confirieron un nuevo auge a la crónica; y después, el género permaneció escondido hasta que encontró su propio territorio en libros y en series de varias entregas en periódicos y revistas. Es entonces cuando aparecen los que hoy consideramos clásicos: Gabriel García Márquez, Tomás Eloy Martínez, Elena Poniatowska y el propio Monsiváis. Un grupo que crece la segunda mitad del siglo XX, como Homero Alsina Thevenet y Enrique Raab en el Río de la Plata o Germán Castro Caycedo, Daniel Samper Pizano 
y Alfredo Molano Bravo en Colombia o Ana Lydia Vega y Luis Rafael Sánchez en Puerto Rico (Jaramillo, 2012, p. 13).

Los excelentes cronistas de hoy en día hoy en día han encontrado espacio es revistas que se la jugaron por los grandes géneros del periodismo, como Etiqueta negra (Perú), Gatopardo (que comenzó en Colombia y ahora existe en Argentina y México), El Malpensante y Soho (Colombia), lamujerdemivida y Orsái (Argentina), Pie izquierdo (Bolivia), Marcapasos (Venezuela), Letras Libres (México), The Clinic y Paula (Chile). Allí han encontrado espacio las crónicas de los argentinos Leila Guerriero, Josefina Licitra y el gran Martín Caparrós, para muchos el más grande de los cronistas argentinos del momento; del chileno Pedro Lemebel; el colombiano Alberto Salcedo Ramos; el mexicano Juan Villoro y el peruano Julio Villanueva Chang (Jaramillo, 2012, p. 14).

En el caso específico de Colombia, se alude a lo positivo que resultó, para la crónica, el distanciamiento entre el periodismo y el dictador Gustavo Rojas Pinilla, quien en 1955 y 1956, respectivamente, mandó a clausurar los dos diarios más importantes del país: El Tiempo y El Espectador. Muchos periodistas se quedaron sin trabajo. El propio García Márquez, quien era corresponsal de El Espectador en Europa, se enfocó más en la literatura y algunos de los que estaban en el país, encontraron espacio en semanarios como Sucesos, creado por periodistas que trabajaban en El Espectador. Uno de sus fundadores es quien ha sido considerado el padre de la crónica policial en Colombia, Felipe González Toledo. Lo acompañaron en la aventura Paulo Forero y el poeta Rogelio Echavarría.

La crónica colombiana salió fortalecida entonces, y fueron apareciendo grandes plumas atraídas por el género, como Iader Giraldo, Gloria Pachón, el gran reportero de reporteros Germán Castro Caycedo, Alegre Levy, Hernando Salguero, Juan Gossaín (quien luego de un paso largo por la radio nacional, ha vuelto por sus fueros), Germán Santamaría (quien escribió las memorables páginas de la tragedia de la erupción de un volcán en Armero, Tolima) y Juan José Hoyos, entre otros, considerados los maestros de un grupo más reciente, encabezado por el ya mencionado Salcedo Ramos, José Alejandro Castaño, José Navia y varios otros.

Una buena aproximación a lo que se entiende como crónica en el caso de Colombia, y que bien puede ser tomado por un buen resumen de todo lo hasta ahora examinado, es el concepto incorporado en el manual de redacción de El Tiempo (2017), principal diario del país:

\footnotetext{
Es un relato de los hechos a partir de una mirada más profunda y detallada del periodista, que acude a técnicas narrativas y a una juiciosa recolección de datos y versiones, para profundizar en los aspectos poco conocidos de personajes y acontecimientos que, sean parte o no de grandes coyunturas noticiosas, tienen alto valor periodístico y merecen ser conocidos por el público.

En este género, los giros narrativos, el suspenso, los diálogos, la descripción de escenas, la presentación de los protagonistas y todos los elementos que caracterizan una buena historia, corresponden a hechos reales y verificables, sin especulaciones ni licencias a la ficción.

La crónica humaniza una noticia, la hace más vívida e intenta involucrar al público en la experiencia del suceso relatado (p. 41).
} 
A lo que solo podría corregírsele que la crónica no solo "intenta", sino que en efecto logra involucrar al lector en la experiencia, de tal manera que él puede llegar a sentir y experimentar, por la magia misma de los recursos literarios, lo que el relato le está trayendo desde el pasado.

Para finalizar, es importante valorar (no se pueden ni se deben dejar por fuera de este recorrido de trasfondo) otros desarrollos periodísticos narrativos distintos de los latinoamericanos. Están nombres como el del ya mencionado Hackl (Saad, 2017), del reportero Ryszard Kapuściński y el perfilador estadounidense Jon Lee Anderson. La producción de los dos últimos es vasta y antológica, y ambos han sido maestros de la Fundación para el Nuevo Periodismo Latinoamericano (FNPI) fundada por García Márquez y que opera desde Cartagena (Colombia). Asimismo, están los “periodistas literarios", agrupados por Sims (1996) en la década de 1980 bajo un paraguas procedimental muy parecido al de Wolfe.

Con Sims y con Kapuściński se exploran, incluso, las dimensiones etnográficas que identifican a la crónica latinoamericana. Sims (1996), por ejemplo, luego de mencionar el énfasis de lo cotidiano en los novelistas y la dinámica informativa de los reporteros, dice:

Los periodistas literarios reúnen las dos formas. Al informar sobre las vidas de las personas en el trabajo, en el amor, o dedicadas a las rutinas normales de la vida, confirman que los momentos cruciales de la vida diaria contienen gran dramatismo y sustancia. En lugar de merodear en las afueras de poderosas instituciones, los periodistas literarios tratan de penetrar en las culturas que hacen posible que funcionen (p. 12).

De manera similar a Wolfe, Sims (1996) identifica y enuncia criterios como el de inmersión en la búsqueda de los datos, la estructura (libre, no apegada a la cronología, sino a las conveniencias del texto), la voz (presencia clara del escritor en el relato, que surge de la experiencia) y la exactitud en términos de la correspondencia entre lo enunciado y lo acontecido: nada de experimentos ficcionales. A eso se suma un sentido de responsabilidad sobre las consecuencias del relato en los lectores y los personajes mismos; y una búsqueda del significado fundamental del reportaje, es decir, de las "realidades simbólicas" a que remite (Sims, 1996, pp. 29-33).

La "inmersión" figura como requisito capital para este tipo de abordaje. Se trata de que el periodista se involucre con el tema de tal forma que eso lo lleve a comprenderlo en sus complejidades, para aprender lo que más pueda sobre los personajes y sus circunstancias. Eso ubica ese tipo de trabajo en dimensiones antropológicas. Los criterios de la antropología son los que nos llevan a conocer las culturas en el entendido de que son tramas de significado tejidas por el propio ser humano en su evolución, como sostuvo Geertz (2003). Este autor nos enseña que el análisis de esas culturas, si bien es una experiencia científica, no lo es tanto para identificar leyes, sino para encontrar explicaciones, a las que se llega mediante la interpretación de las expresiones sociales. Eso era justamente lo que, según Herrscher (2018) hacía Kapuscinsky: 
Siempre había pensado que Kapuscinsky era, en el fondo, uno de los más grandes antropólogos de nuestro tiempo, en muchos sentidos, seguidor de Malinowski, pionero de la etnografía radical y cultor de la ciencia con los pies en el barro, viviendo, comiendo, y durmiendo con los indígenas de Papúa-Nueva Guinea como forma profunda y honesta de conocerlos.

La diferencia es que el reportero no escribía estudios académicos, sino apasionantes relatos narrativos, llenos de descripciones, diálogos y observaciones personales (p. 73).

Enseñanzas todas que (por diferentes vías y en distintos tiempos) fueron llegando (y lo siguen haciendo) a nuestros cronistas de Latinoamérica, a nuestros nuevos "cronistas de las Indias". Con eso como insumo, se han ido formando los criterios que le han dado el sello distintivo al género más artístico del periodismo, al más bello, al que tiene con la estética un compromiso formal, es decir, la crónica.

\section{Conclusiones}

En primer lugar, dada con construcción formal y sus propósitos, la crónica se inscribe dentro de los géneros narrativos. La denominación de esta parcela puede variar según las consideraciones semánticas. En este sentido, habrá quienes consideren más apropiado hablar de "géneros literarios del periodismo", o "géneros creativos". No obstante, es claro que, en su configuración, la crónica se ofrece como un texto de marcada prevalencia estética en la expresión, con una carga marcada de elementos tomados a préstamo de la literatura, y cuya construcción están orientada al propósito de "mostrar" algo. Las explicaciones, contextualizaciones y otros elementos propios de la composición escrita, gravitan en torno a este propósito, y se incorporan para reforzarlo y complementarlo.

La crónica es más antigua que el periodismo. De esta forma, se advierten abordajes asimilables a ella desde los tiempos antiguos, vinculados con hechos y personajes históricos. En su configuración, el elemento tiempo resalta como capital, de lo que da una pista clara su vinculación etimológica con la expresión griega Khronos, que significa y remite a "tiempo"

En cuanto relato (y, en consecuencia, con las teorías de la narrativa) la crónica nos trae del pasado un suceso o nos muestra de nuevo un personaje, un lugar o un tema sobre la base de un significado universal. En este sentido, las consideraciones de Caparrós (2016) se asimilan con las de Bruner (1990) a propósito de la imagen del prisma, la pequeña historia que simboliza a las demás, esa gota que representa a toda la lluvia. Ricoeur (1996) se refiere a esto como la mimesis en términos de la "metáfora de la realidad".

Si bien hay textos producidos en lenguas, tiempos, territorios y culturas que (dada su complejidad y su elaboración artística) pueden ser tenidos como auténticas piezas literarias, y que por eso mismo es tentador ubicarlas bajo un mismo paraguas conceptual, la crónica puede ser vista (y debería serlo) como una creación latinoamericana. Tiene un particular tono, un uso distintivo del lenguaje, un colorido expresivo propio, una voz específica y diferenciada a partir del aprovechamiento de las expresiones que le precedieron. 
En tal sentido, en la crónica latinoamericana confluyen (a manera de complemento o en provecho de lo mejor de cada expresión) la poesía modernista de esta parte del continente, vestida de prosa en las incursiones de Rubén Darío, José Martí, entre otros; y la novela realista europea, hermana del periodismo literario del Viejo Continente, aprehendida y tomada como referente por los cultores del llamado "Nuevo Periodismo" de los Estados Unidos. Los grandes escritores/periodistas del llamado "boom" latinoamericano, con el colombiano Gabriel García Márquez a la cabeza y que inscribieron lo mejor de su producción entre las décadas de 1960 y 1980, se nutrieron de allí.

Por otro lado, la crónica implica una interpretación previa en su abordaje de búsqueda de datos para dar cuenta de la realidad que recrea. Esto quiere decir que el cronista (en sus momentos de inmersión o de trabajo de campo) lee las estructuras de significación en las que cobran sentido las tramas, los personajes, los escenarios y (a partir de esos insumos) reconstruye y trae los acontecimientos ocurridos al presente del lector.

\section{Fuentes consultadas}

Abad, H. et al. (2004). Poder y medios. Bogotá: Aguilar.

Aristóteles. (1987). Poética. Barcelona: Icaria-Bosch.

Aristóteles (1997). Metafísica (Edición trilingüe por Valentín García Yebra). Madrid: Gredos.

Barisone, J. (2003). Literatura y periodismo en las crónicas de Rubén Darío. En Jornadas de Literatura, crítica y medios: perspectivas. Universidad Católica Argentina, Buenos Aires, Argentina. Recuperado de http://bibliotecadigital.uca.edu.ar/ repositorio/ponencias/literatura-y-periodismo-en-las-cronicas.pdf

Bastenier, M. (2001). El blanco móvil. Madrid: Santillana.

Benjamin, W. (2008). El narrador. Santiago de Chile: Ediciones Metales Pesados.

Besa, C. (2014). El ensayo en la teoría de los géneros. Estudios de Literatura, 5, 101-123. Recuperado de https://revistas.uva.es/index.php/castilla/article/view/217

Bruner, J. (1986). Realidad mental y mundos posibles. Barcelona: Gedisa.

Bruner, J. (1990). Actos de significado. Barcelona: Alianza Editorial.

Bruner, J. (2013). La fábrica de historias. Madrid: Fondo de Cultura Económica.

Burke, K. (1969). A Grammar of Motives. Los Ángeles: University of California. 
Callegaro, A. \& Lago, M. (2012). La crónica latinoamericana: cruce entre literatura, periodismo y análisis social. Quórum Académico, (9)2, 246-262. Recuperado de http://www.redalyc.org/articulo.oa?id=199025105004

Caparrós, M. (2016). La crónica. Bogotá: Planeta.

Chillón, A. (2014). La palabra facticia. Literatura, periodismo y comunicación. Barcelona: Universitat Autónoma de Barcelona.

Contursi, M. \& Ferro, F. (2000). La narración, usos y teorías. Bogotá: Grupo Editorial Norma.

Cristoff, M. (Comp.). (2006). Idea crónica. Literatura de no ficción Iberoamericana. Buenos Aires: Beatriz Viterbo.

Derrida, J. (1971). De la gramatología. México, DF: Siglo XXI Editores.

Duch, L. (1997). La educación y la crisis de la modernidad. Barcelona: Ediciones Paidós.

Duch, L. (2008) Estructuras míticas e historia. En B. Solares (Ed.), Antropología simbólica y corporeidad cotidiana (pp. 187-201). México, DF: Universidad Autónoma de México, Centro Regional de Investigaciones Multidisciplinarias.

Duch, L. (2012). Religión y comunicación. Barcelona: Fragmenta Editorial.

Duch, L. (2015). Antropología de la ciudad. Barcelona: Editorial Herder.

EI Tiempo (2017). Manual de redacción (8va ed.). Bogotá: Intermedio Editores.

Fagoaga, C. (1982). Periodismo interpretativo, el análisis de la noticia. Barcelona: Editorial Mitre.

Franco Altamar, J. (2017). El camino de la crónica. Barranquilla: Ediciones Uninorte.

García Márquez, G. (2001). Sofismas de distracción. Sala de Prensa, 29(2). Recuperado de http://www.rebelion.org/hemeroteca/cultura/sofismas_garciamarquez300301.htm

García, V. (Ed.). (2011). Manual de géneros periodísticos (2da. ed.). Bogotá: Ecoe Ediciones, Universidad de La Sabana.

Genette, G. (1991). Ficción y dicción. Madrid: Editorial Lumen.

Genette, G. (1998). Figuras III. Barcelona: Editorial Lumen. 
Geertz, C. (2003). La interpretación de las culturas. Barcelona: Editorial Gedisa.

Gil González, J. (2004). La crónica periodística. Evolución, desarrollo y nueva perspectiva: viaje desde la historia al periodismo interpretativo. Global Media Journal, edición iberoamericana, 1 (1), 26-39.

González, A. (1983). La crónica modernista latinoamericana. Madrid: Ediciones José Porrúa Turanzas.

Grijelmo, A. (1997). El estilo del periodista. Madrid: Grupo Santillana Editores.

Guardela, J. (2001). Escribir es como caminar. Relatoría del Taller de crónica con Alma Guillermo Prieto, realizado por Fundación Gabriel García Márquez para el Nuevo Periodismo Iberoamericano. Cartagena, Colombia.

Guerriero, L. (2009). Frutos extraños. Bogotá: Aguilar.

Guerriero, L. (2015). Zona de obras. Barcelona: Anagrama.

Herrscher, R. (2018). Periodismo narrativo. Bogotá: Ícono Editorial.

Hersey, J. (2009) Hiroshima. Barcelona: Editorial Debolsillo.

Hesíodo (1990). Obras y fragmentos. Madrid: Editorial Gredos.

Jaramillo, D. (Ed). (2012). Antología de crónica latinoamericana actual. Bogotá: Aguilar.

Martínez Albertos, J. (1974). Redacción periodística. Barcelona: ATE.

Meneses. J. (2004). Taller de periodismo narrativo, con Tomás Eloy Martínez. Recuperado de https://fundaciongabo.org/es/recursos/relatorias/taller-de-periodismo-narrativo

Montalbetti, M. (2011). 3 Ideas equivocadas en el lenguaje [video de YouTube]. Recuperado de https://www.youtube.com/watch?v=XdP_dtBvtQo\&t=215s

Palau-Sampio, D. (2018). Las identidades de la crónica: hibridez, polisemia y ecos históricos en un género entre la literatura y el periodismo. Palabra Clave, 21(1), 191-218. doi: 10.5294/pacla.2018.21.1.9

Ramírez, S. (2007). Conversatorio en homenaje a Ryszard Kapuscinsky. Universidad Tecnológica de Cartagena. Colombia.

Monsiváis, C. (1980). A ustedes les consta. México, DF: Ediciones Era. 
Ramos, J. (2003). Desencuentros de la modernidad en América Latina. Santiago de Chile: Editorial Cuarto Propio.

Ricoeur, P. (1996). Tiempo y narración. México, DF: Siglo XXI.

Ronderos, M., León, J., Sáenz, M., Grillo, A. \& García, C. (2002). Cómo hacer periodismo. Bogotá: Aguilar.

Rotker, S. (2005). La invención de la crónica. México, DF: Fondo de Cultura Económica.

Saad, A. (2007). Periodismo y literatura, préstamo entre amigos. Recuperado de https://deperiodismoyliteratura.blogspot.com/2015/03/periodismo-narrativo-yliteratura.html

Salcedo, A. (2011). La crónica, el rostro humano de la noticia. En V. García \& L. Gutiérrez (Eds.), Manual de género periodísticos (pp. 127-154). Bogotá: Ecoe Ediciones.

Samper, D. (2001). Antología de los grandes reportajes colombianos. Bogotá: Aguilar.

San Agustín (2007). Confesiones. Recuperado de http://www.librosenred.com/autores/ sanagustin.html

Serrano, H. (1997). Técnicas de enseñanza del periodismo. México, DF: Editorial Trillas.

Silva, M. (2007). Periodismo y literatura: una cuestión de oficio, pero también de conceptos. Folios. Periodismo para leer, 12-13. pp. 3-6.

Sims, N. (1996). Los periodistas literarios o el arte del reportaje personal. Bogotá: Ancora Editores.

Souvirón, B. (2006). Hijos de Homero. Madrid: Alianza Editorial

Souvirón, B. (2008). El rayo y la espada, I. Madrid: Alianza Editorial.

Souvirón, B. (2012a). Calendario romano (I). Recuperado de http://www.bernardosouviron. com/2012/02/20/calendario-romano-i/

Souvirón, B. (2012b). El viaje como experiencia vital - Gilgamesh - Odiseo. Recuperado de https://pe.ivoox.com/es/bernardo-souviron-el-viaje-como-experiencia-vitalaudios-mp3_rf_1084006_1.html

Villoro, J. (2012). La crónica, ornitorrinco de la prosa. En D. Jaramillo (Ed.), Antología de crónica latinoamericana actual (pp. 577-582). Bogotá: Aguilar.

Wittgenstein, L. (1988). Investigaciones filosóficas. México, DF: Crítica. 
Wolfe, T. (1976). El nuevo periodismo (8va. edición). Barcelona: Anagrama.

Yuste, P. (2011). Lo que cuentan las estrellas. El oficio de los astrónomos en la Antigua Mesopotamia. Espacio, Tiempo y Forma, Serie II, Historia Antigua, t. 24, 83-102. 